\title{
Calorie restriction-mediated restoration of hypothalamic signal transducer and activator of transcription 3 (STAT3) phosphorylation is not effective for lowering the body weight set point in IRS-2 knockout obese mice
}

\author{
Satoko Senda - Atsushi Inoue - Arshad Mahmood • Ryo Suzuki • Nozomu Kamei • Naoto Kubota • \\ Taku Watanabe $\cdot$ Masashi Aoyama $\cdot$ Allah Nawaz Yoshiaki Ohkuma Koichi Tsuneyama • \\ Yukiko Koshimizu · Isao Usui · Kumiko Saeki • Takashi Kadowaki • Kazuyuki Tobe
}

Received: 17 November 2014/ Accepted: 12 January 2015/Published online: 7 February 2015

(C) The Japan Diabetes Society 2015

\begin{abstract}
Aim/hypothesis Lowering the body weight set point is a prerequisite for the maintenance of reduced body weight. In this context, obesity is known to be strongly linked to leptin resistance, and it remains to be clarified whether recovery from leptin resistance might lower the body weight set point to allow sustained body weight loss.

Methods Obese IRS-2 knockout $\left(I R S-2^{-1-}\right)$ mice were subjected to calorie restriction (CR) or $\beta 3$-adrenergic receptor (AR) agonist treatment. The physiological effects of leptin, hypothalamic leptin signaling, and alterations of the body weight set point were evaluated.

Results In the CR mice, recovery from acquired leptin resistance was observed, as shown by the restoration of the suppressive effects of leptin on food intake and weight gain, as well as the recovery of signal transducer and activator of transcription 3 (STAT3) phosphorylation. Nevertheless, the body weight quickly rebounded to the
\end{abstract}

S. Senda - A. Mahmood · A. Nawaz · Y. Koshimizu · I. Usui ·

K. Tobe $(\bowtie)$

First Department of Internal Medicine, Graduate School of Medicine and Pharmaceutical Science for Research, University of Toyama, 2630 Sugitani, Toyama-City, Toyama 930-0194, Japan

e-mail: tobe@med.u-toyama.ac.jp

A. Inoue $\cdot$ R. Suzuki $\cdot$ N. Kamei $\cdot$ N. Kubota $\cdot$ T. Watanabe M. Aoyama $\cdot$ T. Kadowaki

Department of Diabetes and Metabolic Diseases, Graduate

School of Medicine, University of Tokyo, Tokyo, Japan

Present Address:

N. Kamei

Department of Endocrinology and Diabetology, National

Hospital Organization, KURE Medical Center, Kure, Japan original body weight after cessation of the CR, suggesting that CR failed to overcome the primary defect in IRS-2/ phosphatidylinositol 3-kinase (PI3K) signaling. On the other hand, after 2 weeks $\beta 3$-AR agonist treatment, the mice began to lose body weight, indicating that the treatment was able to overcome the primary defect in IRS-2/ PI3K signaling and lower the body weight set point.

Conclusions/interpretation Recovery of acquired leptin resistance does not lead to a resetting of the body weight set point in obese IRS-2/PI3K-defective mice. $\beta 3$-AR agonist treatment may act on some pathways distal to or independent of PI3K and/or STAT3, inducing resetting of the body weight set point.

Keywords $\beta 3$-adrenergic receptor agonist - Body weight set point $\cdot$ Calorie restriction $\cdot I R S-2^{-/-}$mice $\cdot$ Leptin resistance $\cdot$ Signal transducer and activator of transcription 3 (STAT3)

Present Address:

M. Aoyama

First Institute of New Drug Discovery, Otsuka Pharmaceutical

Co., Ltd., Tokyo, Japan

Y. Ohkuma

Laboratory of Gene Regulation, Graduate School of Medicine and Pharmaceutical Science for Research, University of Toyama, Toyama, Japan

K. Tsuneyama

Department of Diagnostic Pathology, University of Toyama, Toyama, Japan

K. Saeki

Department of Disease Control, Research Institute, National

Center for Global Health and Medicine, Tokyo, Japan 


\section{Introduction}

Maintenance of a reduced body weight is one of the most critical issues in the treatment of obesity, because a considerable number of obese patients suffer from rebound obesity. This phenomenon can be explained by the socalled "set point theory" [1, 2], which was proposed based on animal studies, and proposes that the body has its own body weight set point to maintain a specific level of adiposity by a proportional feedback system. The lipostat model or the set point theory beautifully explains the common phenomenon of weight regain after acute weight loss and the failure of dieting to induce sustained weight loss despite various trials to promote sustained weight loss [3]. Currently, however, alternative models, including the "settling point theory" and the "dual intervention point model", have been proposed to explain the obesity pandemic in our society [4].

Leptin is an adipocytokine that functions as the afferent signal in a negative feedback loop regulating body weight [5-8]. Leptin serves to maintain a relatively constant weight in mammals, and has been regarded as a central player in the lipostat system, which was recently lent support by a mathematical model [9]. At their body weight set point, an individual produces a given amount of leptin in order to maintain a balanced state of energy homeostasis by regulating food intake and energy expenditure. Thus, the degree of leptin action, which is determined by the amount of leptin secreted from the adipocytes and the leptin sensitivity of the target tissues, is one of the major factors that determines each individual's body weight set point [9]. In fact, the discovery of individuals with loss-of-function mutations in the gene encoding leptin [10] and mutations in other genes in the neural pathways downstream of leptin have lent strong support to the role of leptin in determining the body weight set point [11].

In addition to genetic defects of the leptin signaling molecules, acquired [12] or cellular leptin resistance [13] has also been recognized, which refers to a diminished response to the signaling or weight-reducing effect of exogenous leptin associated with obesity [14-17]. It is widely accepted that acquired leptin resistance augments weight gain [13]. However, it remains unclear whether acquired leptin resistance directly determines the body weight set point or whether there are certain intermediary factors that determine the body weight set point. Currently, hyperleptinemia, but not obesity per se, is reported to be a major determinant of acquired leptin resistance through its downregulation of signal transducer and activator of transcription 3 (STAT3) phosphorylation in the hypothalamus [18]. Importantly, this report also demonstrated that a high fat diet (HFD)-induced upward shift of the body weight set point is not affected by the STAT3 phosphorylation levels in the hypothalamus. This observation led us to investigate whether acquired leptin resistance might actually affect the body weight set point.

Obesity promotes a number of cellular processes that attenuate leptin signaling and augment body weight gain. STAT3 and phosphatidylinositol 3-kinase (PI3K) signaling are the two major arms of leptin signaling [5, 19-22]. Although prolonged hyperleptinemia has been shown to impair STAT3 phosphorylation in the hypothalamus [18], obesity per se has been shown to hamper PI3K signaling events [23]. To precisely understand the role of acquired STAT3 phosphorylation defects in the development of obesity and of recovered STAT3 signaling in reducing the body weight set point, an animal model in which the role of STAT3 can be analyzed independently of the primary cause of obesity was desired, and IRS-2 knockout (IRS$2^{-I-}$ ) mice were established as an ideal model for this purpose. These mice show severely reduced leptin-stimulated PI3K activity, exhibit increased adiposity with hyperleptinemia, and are resistant to peripherally administered leptin, without having any genetic defects in the STAT3 signaling pathway [20, 24-28].

$\beta 3$-adrenergic receptor (AR) agonists are known as antidiabetic and anti-obesity drugs because they induce lipolysis in white adipose tissue (WAT) and thermogenesis in brown adipose tissue (BAT) $[29,30]$. In humans, they are known to improve the insulin sensitivity by increasing fat oxidation [31]. Notably, specific $\beta 3$-AR agonists have also been shown to ameliorate the hyperleptinemia associated with increased adiposity in obese rodents. In fact, the $\beta 3$ AR agonist AJ-9677 has been shown to decrease the mRNA expression level of leptin in the epididymal WAT of $\mathrm{KK}-\mathrm{A}^{\mathrm{y}} / \mathrm{Ta}$ mice [32]. However, it has not yet been clarified whether $\beta 3$-AR agonists can improve leptin resistance, especially at the level of STAT3 phosphorylation. It also remains to be clarified whether $\beta 3$-AR agonists can alter the body weight set point to allow sustained body weight loss.

To compare the effect of calorie restriction (CR) and $\beta 3$-AR agonist treatment on the recovery of leptin sensitivity, we established, for the first time, an animal system of $I R S-2^{-1-}$ mice that serves as an ideal model for differential analysis of the significance of STAT3 signaling defects and PI3K signaling defects in the determination of the body weight set point [24, 27]. In the present study, we showed that amelioration of acquired leptin resistance per se is not sufficient to reduce an elevated body weight set point in obese animals, and that other pathways distal to or independent of PI3K and/or STAT3 signaling events are crucial for the maintenance of reduced body weight. 


\section{Methods}

\section{Animals}

Male IRS $-2^{+/-}$mice on a C57BL/6J background were intercrossed to obtain the IRS $-2^{-/-}$and $I R S-2^{+/+}$mice (wildtype) used for this study. The mice were maintained under a 12-h light/dark cycle and given regular chow (MF; Oriental Yeast Co. Ltd., Tokyo, Japan) consisting of $22.8 \%$ (wt/wt) protein, $2.8 \%$ fiber, $5.8 \%$ ash, $55.2 \%$ carbohydrates, $5.1 \%$ fat, and $8.4 \%$ water. Then, 12 -week-old $I R S$ $2^{-1-}$ mice were divided into two groups, as follows, for the calorie restriction experiment: an ad libitum-fed group and a calorie-restricted group. The calorie-restricted group was given around $3.0 \mathrm{~g} /$ day of chow for 3 weeks to adjust their body weight to that of the wild-type mice. For the $\beta 3$-AR agonist injection study, 12 -week-old IRS-2 $2^{-I}$ mice were divided into treatment and vehicle groups. The treatment group received intraperitoneal administration of CL316243 , a $\beta 3$-AR agonist $(0.3 \mathrm{mg} / \mathrm{kg}$ body weight; SigmaAldrich, St. Louis, MO, USA), while the vehicle-treated group received physiological saline alone each morning. The body weight and food intake were monitored at 09:00 $\mathrm{h}$ throughout the study period. The animal care methods and experimental procedures employed were approved by the Animal Care Committee of the University of Toyama.

Determination of the glucose, insulin, and leptin levels

Blood samples from the IRS-2 ${ }^{-/-}$and wild-type mice were collected between 09:00 and 11:00 h before and after calorie restriction and $\beta 3-\mathrm{AR}$ agonist treatment. The blood glucose concentration was measured using an automatic blood glucose meter (FreeStyle Sensor; NIPRO, Osaka, Japan). The serum insulin levels were determined using the Mouse Insulin ELISA kit (AKRIN-031; Shibayagi, Gunma, Japan). The serum leptin levels were measured using an enzyme-linked immunosorbent assay-based Quantikine Mouse Leptin Immunoassay kit (R\&D Systems, Minneapolis, MN, USA), according to the manufacturer's instructions.

Evaluation of the effects of leptin administration

Recombinant mouse leptin (PeproTech EC Ltd., London, UK) was dissolved in distilled water, and leptin or saline was injected intraperitoneally into the $I R S-2^{-1-}$ and wild-type mice at 20:00 h. Food intake and body weight gain were monitored from 20:00 to $08: 00 \mathrm{~h}$ to evaluate the responses of the two groups to the leptin injection.
Immunoblotting

After food deprivation for $2-3 \mathrm{~h}$, the $I R S-2^{-/-}$and wild-type mice were administered intraperitoneal injections of recombinant leptin or saline. The hypothalamus was removed at $4 \mathrm{~h}$ after the injection and immediately homogenized in ice-cold buffer A (25 mM Tris- $\mathrm{HCl}$ [pH7.4], $10 \mathrm{mM}$ sodium orthovanadate, $10 \mathrm{mM}$ sodium pyrophosphate, $100 \mathrm{mM}$ sodium fluoride, $10 \mathrm{mM}$ EDTA, $10 \mathrm{mM}$ EGTA, and $1 \mathrm{mM}$ phenylmethyl sulfonyl fluoride) using a Multi-Beads Shocker (Yasui-kikai, Osaka, Japan). Immunoblotting was performed as described previously [27]. The antibodies to STAT3 and phospho-STAT3 (Tyr705) were purchased from Cell Signaling Technology (Beverly, MA, USA).

\section{Phosphatidylinositol 3-kinase (PI3K) assay}

The hypothalamus was removed $1 \mathrm{~h}$ after the intraperitoneal injection of leptin and homogenized and centrifuged at $15,000 \mathrm{rpm}$ for $30 \mathrm{~min}$ in ice-cold buffer A. PI3K activity was then measured as described previously [33].

Quantitative polymerase chain reaction with reverse transcription (RT-PCR)

$I R S-2^{-/-}$and wild-type mice were subjected to food deprivation for $2-3 \mathrm{~h}$ and injected intraperitoneally with recombinant leptin or saline. The hypothalamus was then removed. Following the extraction of total RNA and synthesis of cDNA, RT-PCR was performed as described previously [34]. The results were normalized against the gene expression of $18 \mathrm{~S}$.

Data analysis

Statistical analyses were performed using Student's $t$ test or ANOVA, followed by the Tukey-Kramer test. The results are presented as the mean \pm SEM.

\section{Results}

Calorie restriction effectively decreased the body weight and fat mass, improved glucose metabolism, and ameliorated hyperleptinemia in the IRS-2 $2^{-I-}$ mice

Consistent with our previous report [24], the body weight of the IRS-2 $2^{-I-}$ mice was higher than that of the wildtype mice from 8 weeks of age. When the IRS $-2^{-1-}$ mice were subjected to calorie restriction for 3 weeks, their body weight decreased to become almost comparable to that of the wild-type mice (Fig. 1a). The calorie-restricted 


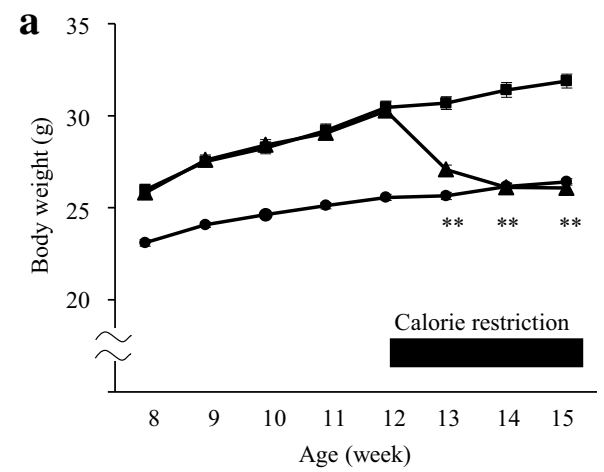

c
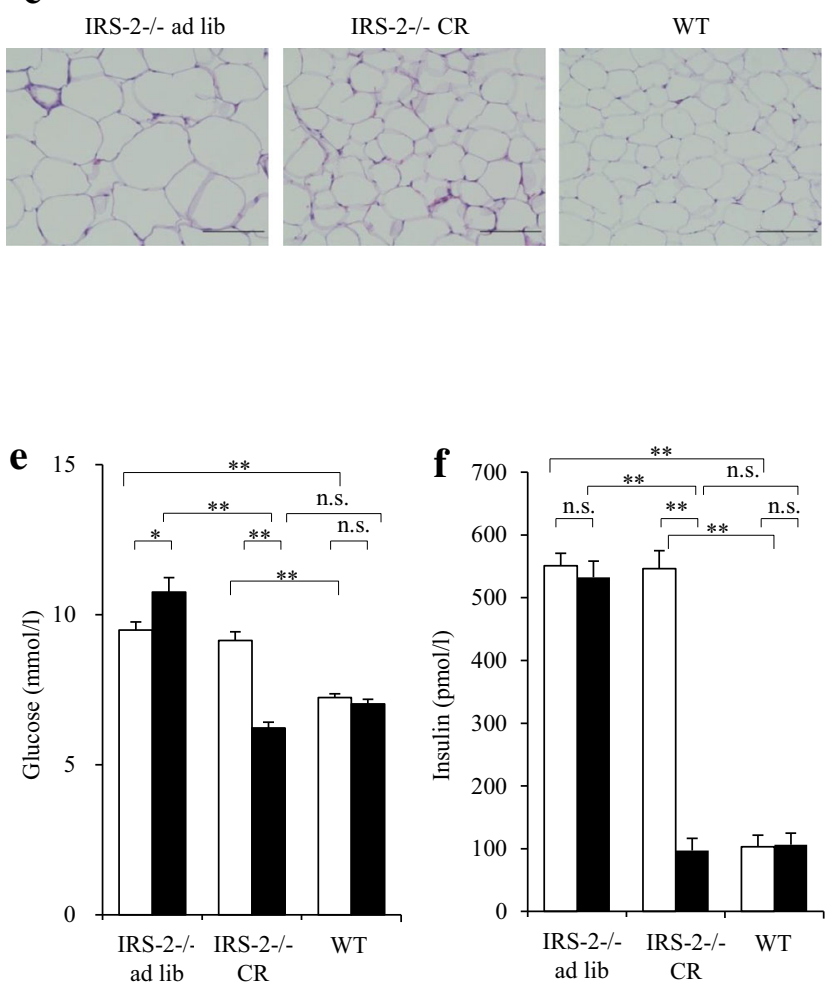

b

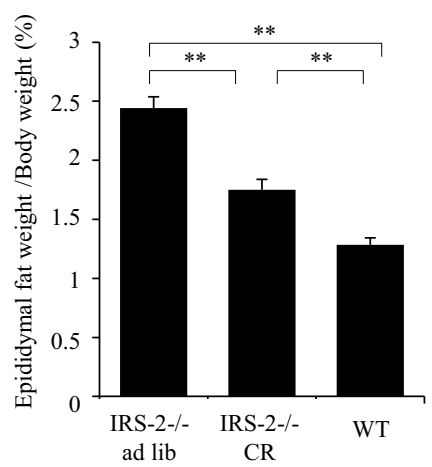

d
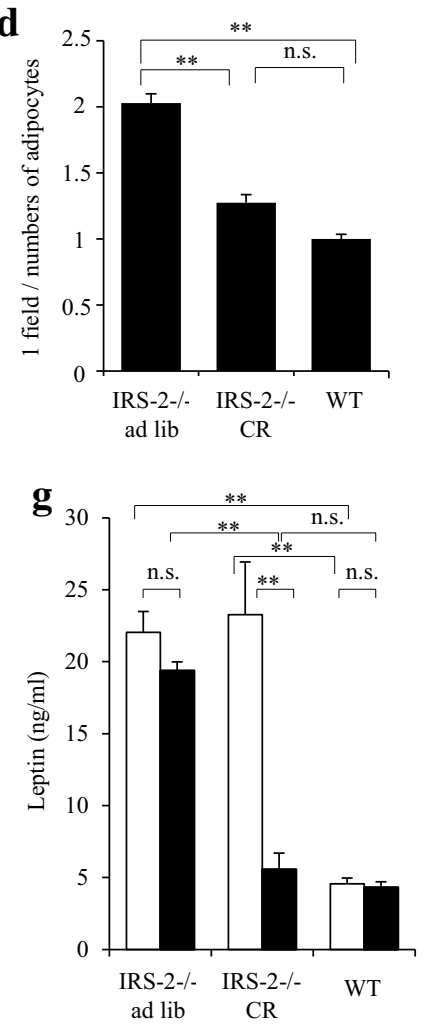

Fig. 1 Calorie restriction decreased the body weight and fat mass effectively, improved glucose metabolism, and decreased the serum leptin levels in the IRS $-2^{-1-}$ mice. a Changes in the body weight of the ad libitum-fed IRS-2 $2^{-1-}$ mice (squares), calorie-restricted IRS$2^{-l-}$ mice (triangles), and wild-type mice (circles) $(n=20-30)$. b Weight ratios of the epididymal fat tissue per body weight in the ad libitum-fed $I R S-2^{-/-}$mice $\left(I R S-2^{-1-}\right.$ ad lib), calorie-restricted $I R S-2^{-l-}$ mice $\left(I R S-2^{-l-} C R\right)$, and wild-type mice (WT). c HE-stained pictures of the epididymal WAT after 3 weeks of calorie restriction in the ad libitum-fed $I R S-2^{-I-}$ mice $\left(I R S-2^{-l-}\right.$ ad lib), calorie-restricted $I R S-2^{-l-}$ mice $\left(I R S-2^{-l-} C R\right)$, and wild-type mice $(W T)$. The scale for

$I R S-2^{-1-}$ mice showed decreased epididymal WAT weight, with smaller adipocytes (Fig. 1b-d). They also showed improved glucose metabolism and lowered leptin levels as compared to the ad libitum-fed $I R S-2^{-1-}$ mice (Fig. 1e-g). the bar is $200 \mu \mathrm{m}$. d Statistical analysis of the adipocyte size. Data are presented as a fraction of the number of adipocytes visible in a field. The adipocytes were counted in three other fields in each mouse $(n=3)$. The concentrations of e blood glucose $(n=30-40)$, $\mathbf{f}$ serum insulin, and $\mathbf{g}$ leptin in the ad libitum-fed $I R S-2^{-/-}$mice $\left(I R S-2^{-/-} \mathrm{ad}\right.$ lib), calorie-restricted $I R S-2^{-l-}$ mice $\left(I R S-2^{-1-} C R\right)$, and wild-type mice $(W T)$ are shown $(n=5-10)$. White bars 12 weeks of age, black bars 15 weeks of age. Data are presented as the mean \pm SEM. $* * p<0.01, * p<0.05$. $* * p<0.01$ in a, ad libitum-fed vs. calorierestricted $I R S-2^{-1-}$ mice

Calorie restriction ameliorated leptin resistance in the IRS $-2^{-/-}$mice

We next compared the physiological effects of leptin on the food intake and body weight gain in the calorie-restricted 
and ad libitum-fed $I R S-2^{-1-}$ mice. Injection of leptin at a dose of $20 \mathrm{mg} / \mathrm{kg}$ body weight, but not a dose of $10 \mathrm{mg} / \mathrm{kg}$ body weight, significantly reduced the food intake and body weight gain in the calorie-restricted $I R S-2^{-1-}$ mice as compared with those in the ad libitum-fed $I R S-2^{-1-}$ mice (Fig. 2). These results suggest that-at least in partcalorie restriction ameliorated leptin resistance in the IRS$2^{-1-}$ mice, consistent with a previous report [35].

Calorie restriction restored the leptin-induced STAT3 phosphorylation defect and leptin-stimulated gene expressions in the hypothalamus of the $I R S-2^{-/-}$mice

To clarify the molecular mechanism of the partial amelioration of leptin resistance in the calorie-restricted IRS- $2^{-l-}$ mice, we investigated STAT3 phosphorylation and the gene expressions of appetite-controlling neuropeptides. Leptin signaling is known to induce the gene expression of pro-opiomelanocortin (POMC), an anorexigenic neuropeptide, and to reduce that of neuropeptide Y (NPY), an orexigenic neuropeptide. We found a marked recovery of STAT3 phosphorylation (Fig. 3a, b) associated with recovery of the effects of leptin on the expressions of POMC and NPY (Fig. 4a, b) in the calorie-restricted $I R S-2^{-1-}$ mice (almost comparable to the findings in the wild-type mice) as compared with those in the ad libitum-fed IRS$2^{-1-}$ mice. This recovery occurred without improvement of the severely impaired PI3K activity (Fig. 3c, d). Suppressor of cytokine signaling 3 (SOCS3) is induced by activated STAT3 and is a negative regulator of leptin signaling, so
Fig. 2 Calorie restriction improved leptin resistance in $I R S-2^{-1-}$ mice. Changes in a food intake and $\mathbf{b}$ body weight during the $12-\mathrm{h}$ period after leptin (10 or $20 \mathrm{mg} / \mathrm{kg}$ body weight) or saline injection in the ad libitum-fed $I R S-2^{-1-}$ mice $\left(I R S-2^{-1-}\right.$ ad lib), calorierestricted $I R S-2^{-1-}$ mice (IRS$\left.2^{-/-} C R\right)$, and wild-type mice (WT) $(n=5-18)$. Data are presented as the mean \pm SEM. $* * p<0.01$
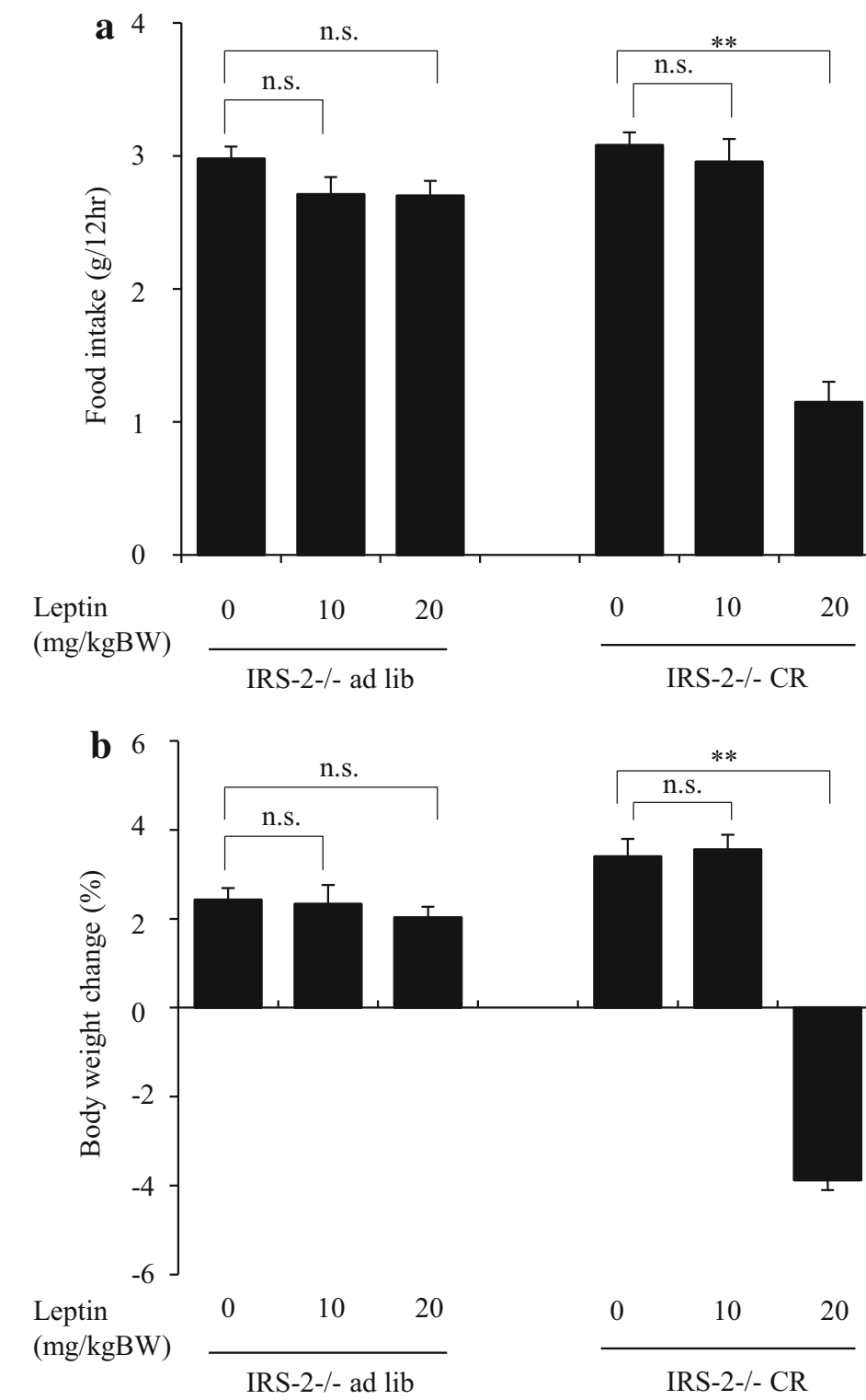

IRS-2-/- ad lib
IRS-2-/- CR

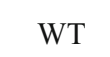

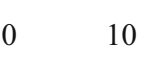
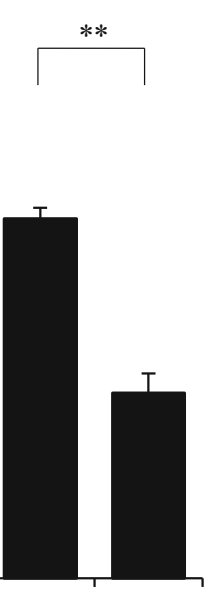

10 

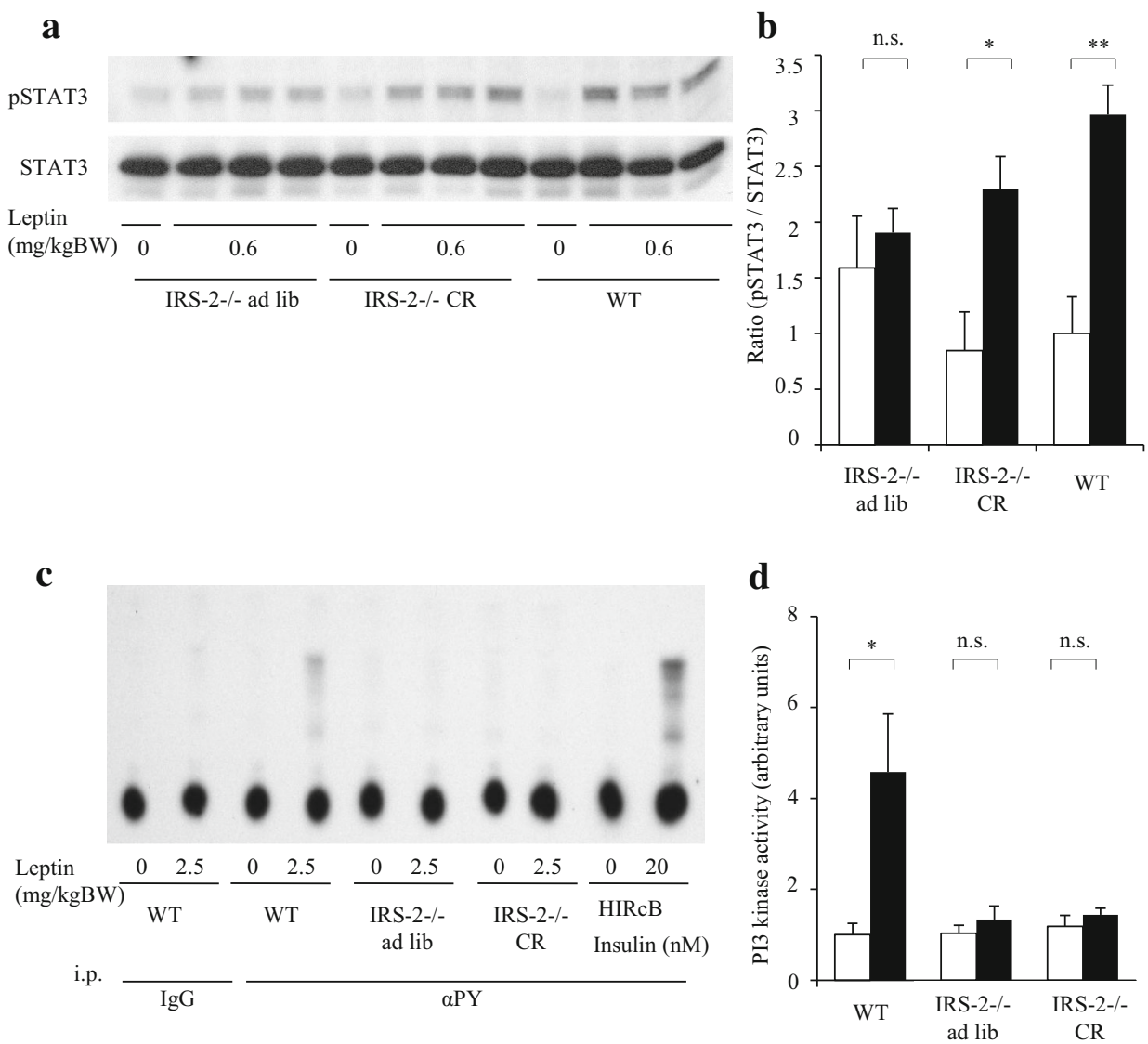

Fig. 3 Calorie restriction restored leptin-induced STAT3 phosphorylation but exerted no effect on the PI3K activity in the hypothalamus of $I R S-2^{-1-}$ mice. a Immunoblotting of phospho- or nonphospho-STAT3 in hypothalamus of ad libitum-fed IRS-2 $2^{-1-}$ mice (IRS-2 $2^{-I-}$ ad lib), calorie-restricted IRS-2 $2^{-/-}$mice (IRS- $2^{-1-} C R$ ), and wild-type mice (WT) after leptin injection. b Intensities of the bands corresponding to phospho-specific STAT3 corrected for nonphospho-STAT3 expression. c PI3K activity in the hypothalamus of

that it occurs in the feedback loop in the leptin-induced Janus kinase (JAK)2-STAT3 pathway. The basal gene expression of SOCS3 was increased in the ad libitum-fed IRS-2 $2^{-/-}$mice as compared with that in the wild-type mice. In contrast, calorie-restricted $I R S-2^{-/-}$mice showed a reduction in the basal SOCS3 gene expression relative to that in the ad libitum-fed $I R S-2^{-/-}$mice. In addition, the responsiveness of leptin-induced SOCS3 gene expression was enhanced in the calorie-restricted IRS-2 $2^{-I-}$ mice (Fig. 4c).

Calorie restriction could not lower the body weight set point in the IRS $-2^{-I-}$ mice

To assess whether the calorie restriction-induced improvement in leptin resistance could reset the body weight set point, we next examined the body weight after releasing calorie restriction. IRS-2 $2^{-/-}$mice were subjected to calorie the wild-type mice (WT), ad libitum-fed IRS-2 $2^{-1-}$ mice $\left(I R S-2^{-1-}\right.$ ad lib) and calorie-restricted IRS-2 $2^{-1-}$ mice $\left(I R S-2^{-1-} C R\right)$. The PI3K activity in insulin-stimulated HIRcB cells-the positive control-is shown on the right side of the picture. d Bar graph showing the PI3K activity in each group. Data are presented as the mean \pm SEM of four independent experiments. White bars saline injection, black bars leptin injection. $* * p<0.01, * p<0.05$

restriction for 3 weeks; by the end of this period their body weight had become almost comparable to that of the wildtype mice (Fig. 5a). The IRS-2 $2^{-1-}$ mice were then released from the calorie restriction and fed ad libitum. Food intake per day in the calorie-restricted IRS-2 $2^{-1-}$ mice significantly increased during the first week after release from calorie restriction as compared with that in the ad libitum-fed IRS $-2^{-1-}$ mice (Fig. $5 \mathrm{~b}$ ). The body weight of the calorie-restricted IRS$2^{-1-}$ mice immediately rebounded toward that of the ad libitum-fed IRS-2 $2^{-/-}$mice, with the body weights of the two groups remaining similar during the latter course (Fig. 5a).

Effects of $\beta 3$-AR agonist treatment on the body weight, fat mass, hyperleptinemia, and glucose metabolism

We next addressed the effect of a $\beta 3$-AR agonist - an alternative treatment to calorie restriction for obesity—on the 
Fig. 4 Calorie restriction increased POMC gene expression, decreased NPY gene expression, and restored SOCS3 gene expression after intraperitoneal leptin administration in the hypothalamus of $I R S-2^{-1-}$ mice. The gene expressions of a POMC, b NPY, and c SOCS3 in the hypothalamus of the ad libitum-fed $I R S-2^{-/-}$mice $\left(I R S-2^{-I-}\right.$ ad lib), calorierestricted IRS-2 $2^{-l-}$ mice (IRS$2^{-/-} C R$ ), and wild-type mice (WT) were measured using quantitative RT-PCR and were normalized against the gene expression of $18 \mathrm{~S}$ ( $n=9-12$ per group). White bars saline injection, black bars leptin injection. Data are presented as the mean \pm SEM. $* * p<0.01$, $* p<0.05$ $\mathbf{a}$

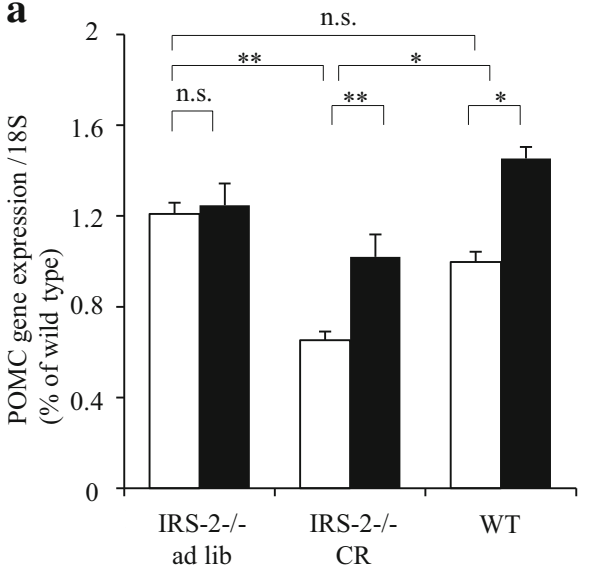

c

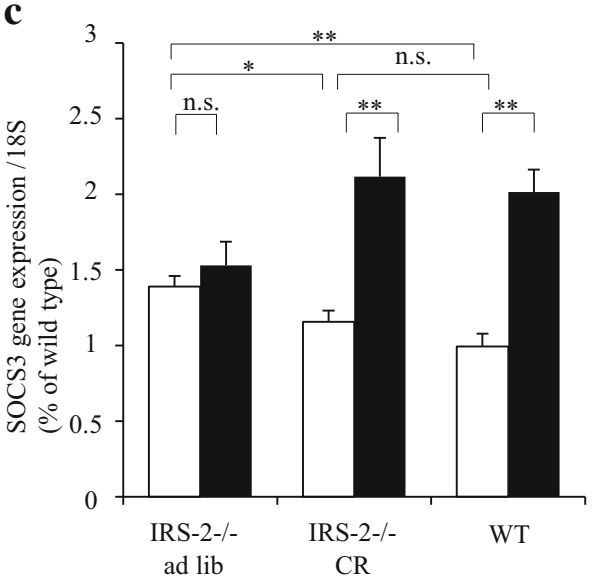

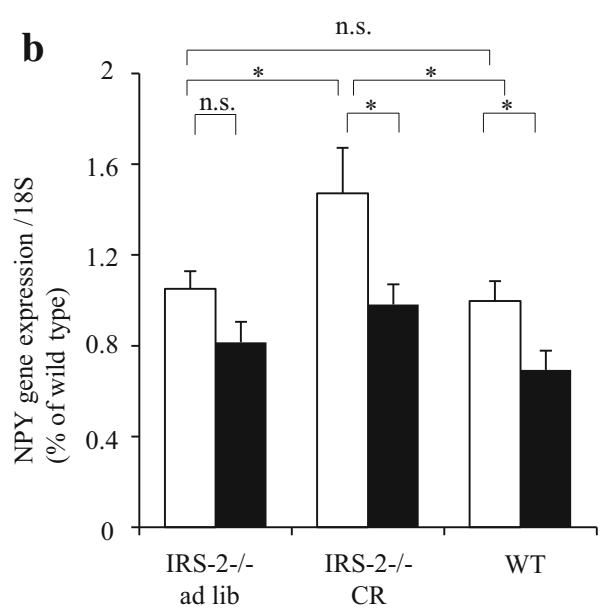
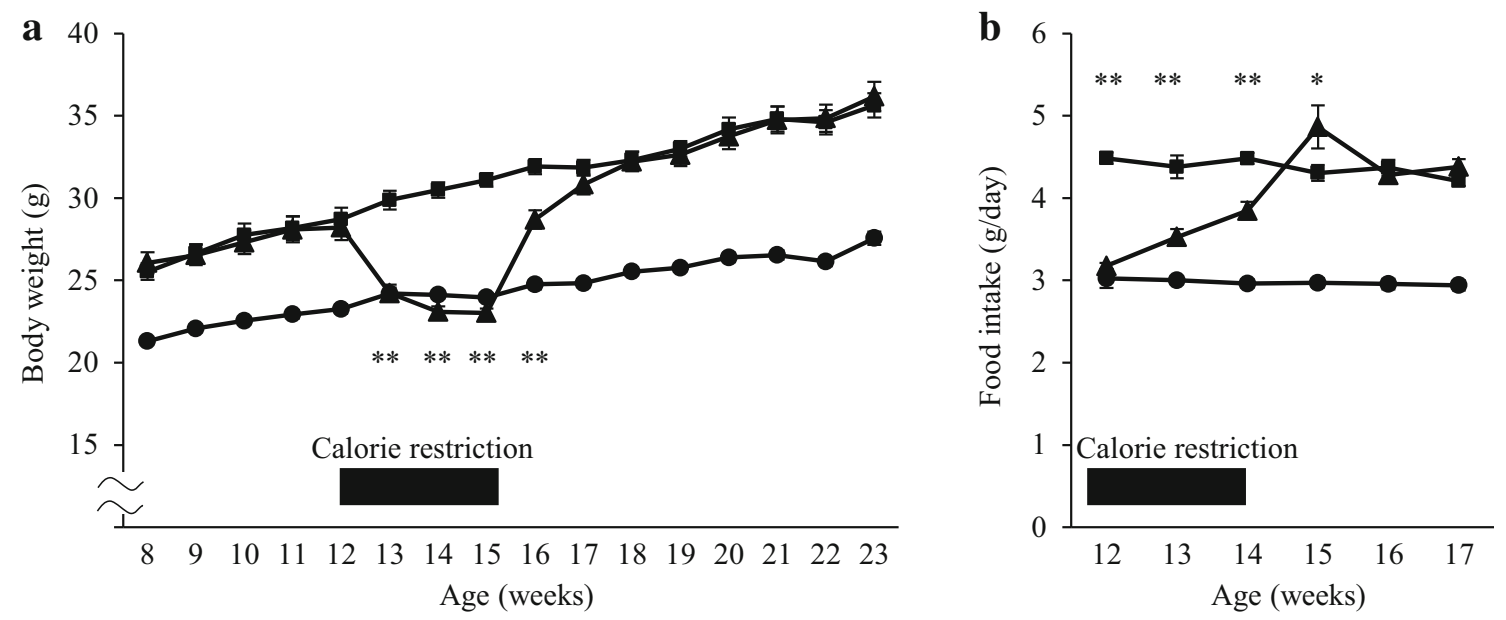

Fig. 5 Calorie restriction could not reset the body weight set point in the IRS $-2^{-I-}$ mice. Changes in the a body weight and $\mathbf{b}$ food intake (g/day) of the ad libitum-fed IRS-2 $2^{-1-}$ mice $\left(I R S-2^{-1-}\right.$ ad lib; squares), calorie-restricted IRS-2 $2^{-1-}$ mice (IRS-2 ${ }^{-1-} C R$; triangles),

body weight and leptin resistance. We administered the $\beta 3$ AR agonist CL-316243 by intraperitoneal injection. During the first 2 weeks of CL-316243 treatment, the body weight and wild-type mice (WT; circles) during and after releasing them from 3 weeks of calorie restriction $(n=9-10$ per group). Data are presented as the mean \pm SEM. $* * p<0.01$, $* p<0.05$, ad libitumfed vs. calorie-restricted $I R S-2^{-1-}$ mice

of the CL-316243-treated IRS-2 $2^{-1-}$ mice remained comparable to that of the vehicle-treated $I R S-2^{-1-}$ mice (Fig. 6a), despite the increased average food intake of the 


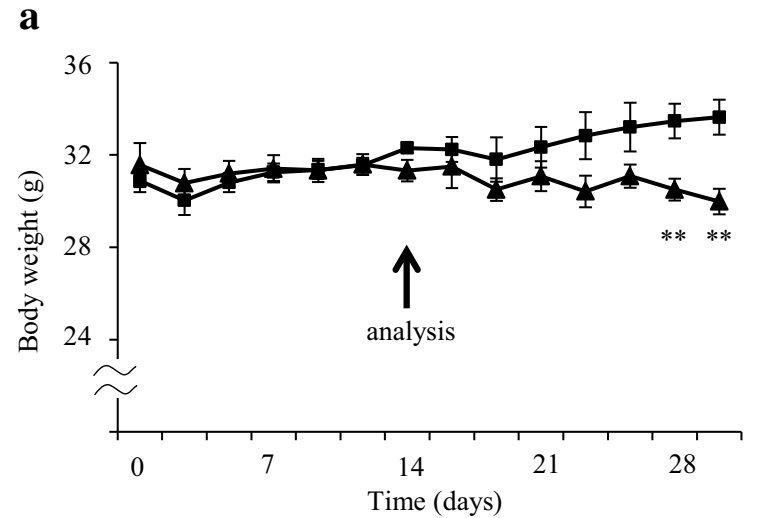

(CL 0.3mg / kg BW i.p. administration)

c

IRS-2-/- vehicle

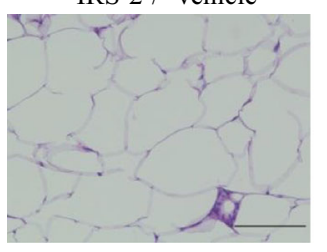

IRS-2-/- CL-316243
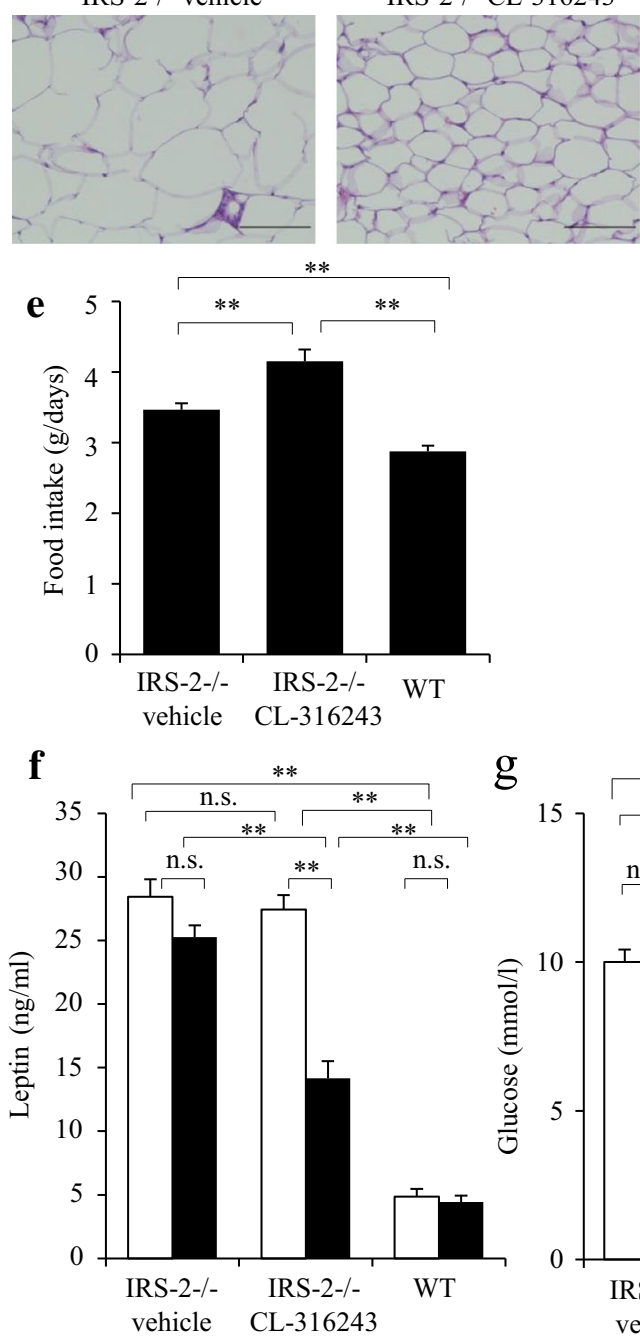

g

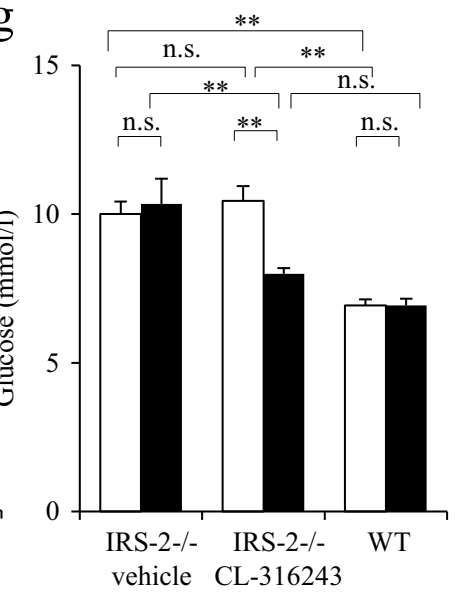

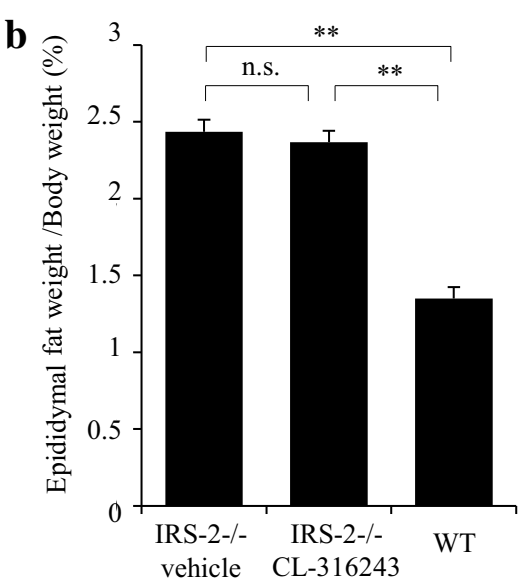

d

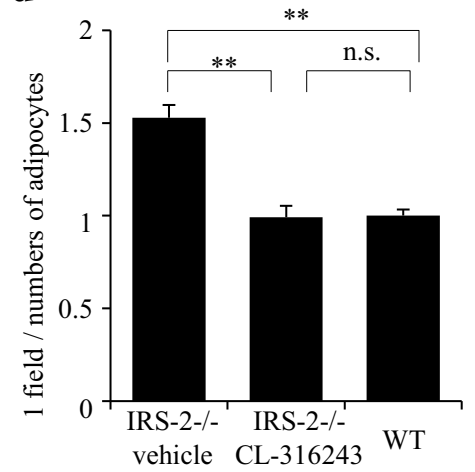

h

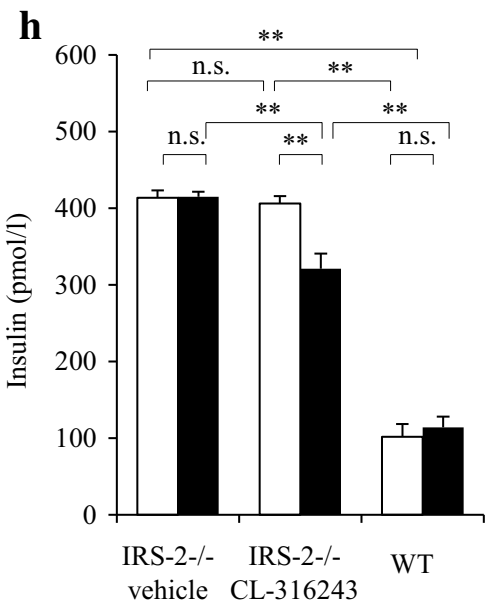


4Fig. $6 \beta 3$-AR agonist treatment increased food intake while exerting no effect on the body weight, improved glucose metabolism, and decreased serum leptin levels in $I R S-2^{-I-}$ mice. a Changes in the body weight of the IRS $-2^{-/-}$mice treated with the $\beta 3$-AR agonist CL316243 (triangles) or vehicle (squares) for 30 days $(n=5$ per group). b Weight ratios of the epididymal fat tissue per body weight on day 14 in the vehicle-treated IRS-2 $2^{-/-}$mice (IRS-2 $2^{-1-}$ vehicle), $\beta 3-\mathrm{AR}$ agonist-treated IRS-2 $2^{-/-}$mice $\left(I R S-2^{-/-} C L-316243\right)$, and wild-type mice $(W T)$. c HE-stained pictures of the epididymal WAT after 2 weeks of $\beta 3$-AR agonist treatment in the vehicle-treated IRS$2^{-1-}$ mice (IRS-2 $2^{-1-}$ vehicle), $\beta 3$-AR agonist-treated IRS-2 $2^{-1-}$ mice $\left(I R S-2^{-1-} C L-316243\right)$, and wild-type mice $(W T)$. The scale for the bar is $200 \mu \mathrm{m}$. d Statistical analysis of the adipocyte size. The data are presented as fractions of the number of adipocytes in a field. The adipocytes were counted in three other fields in each mouse $(n=3)$. e Average food intake $(\mathrm{g} / 12 \mathrm{~h})$ during $\beta 3$-AR agonist or vehicle treatment ( $n=12-14$ per group). Concentrations of $\mathbf{f}$ leptin, $\mathbf{g}$ blood glucose, and $\mathbf{h}$ insulin in the vehicle-treated IRS $-2^{-1-}$ mice $\left(I R S-2^{-1-}\right.$ vehicle), $\beta 3-\mathrm{AR}$ agonist-treated IRS-2 $2^{-1-}$ mice $\left(I R S-2^{-/-} C L\right.$ $316243)$, and wild-type mice (WT) ( $n=15-20$ per each group). White bars before treatment, black bars after 14 days of treatment. Data are presented as the mean \pm SEM. $* * p<0.01$

CL-316243-treated IRS-2 $2^{-1-}$ mice as compared to the vehicle-treated $I R S-2^{-/-}$mice (Fig. 6e). It has been reported that CL-316243 directly suppresses leptin production in the adipocytes [36]. CL-316243 treatment significantly ameliorated the hyperleptinemia (Fig. 6f). A reduction in the size of the adipocytes was observed (Fig. 6c, d), as previously reported [32], without any effect on the body weight (Fig. 6a) or the epididymal WAT weight ratio relative to the total body weight in the IRS-2 $2^{-1-}$ mice (Fig. 6b). CL316243 also improved the glucose metabolism in the IRS$2^{-1-}$ mice (Fig. 6g, h). After the mice had been treated with CL-316243 for another 2 weeks, the body weight of the mice began to drop significantly (Fig. 6a). Thus, we performed the following analysis at day 14 of CL-316243 treatment, as this was the timepoint at which CL-316243 treatment was ameliorating hyperleptinemia but was not affecting body weight.

Chronic $\beta 3$-AR agonist treatment improved leptin resistance in the $I R S-2^{-1-}$ mice

To assess the effect of $\beta 3-\mathrm{AR}$ agonist treatment on leptin resistance, we next examined the effects of leptin on the food intake and body weight gain induced by $\beta 3-\mathrm{AR}$ agonist treatment in the IRS-2 $2^{-/-}$mice. Injection of leptin at a dose of $20 \mathrm{mg} / \mathrm{kg}$ body weight, but not at a dose of $5 \mathrm{mg} / \mathrm{kg}$ body weight, significantly reduced the food intake and body weight gain in the CL-316243-treated IRS-2 $2^{-/-}$ mice as compared with that in the vehicle-treated IRS-2 $2^{-1-}$ mice (Fig. 7). These results indicate that-at least in part$\beta 3$-AR agonist treatment ameliorated leptin resistance in the $I R S-2^{-1-}$ mice.
Chronic $\beta 3-\mathrm{AR}$ agonist treatment restored the leptininduced STAT3 phosphorylation defect and leptinstimulated gene expressions in the hypothalamus of the IRS $-2^{-/-}$mice

We next investigated the effect on STAT3 phosphorylation and expression of the genes encoding the appetite-controlling neuropeptides. We found a marked recovery of STAT3 phosphorylation (Fig. 8a, b) associated with the recovery of the effects of leptin on the expression of POMC and NPY (Fig. 9a, b) in the CL-316243-treated $I R S-2^{-1-}$ mice as compared with the findings in the vehicle-treated $I R S-2^{-1-}$ mice. This recovery was not, however, associated with an improvement in the severely impaired PI3K activity (Fig. 8c).

We next tested the expression of SOCS3 in the hypothalamus. The basal gene expression of SOCS3 was increased in vehicle-treated $I R S-2^{-1-}$ mice as compared with that in the wild-type mice. In contrast, CL-316243-treated $I R S-2^{-1-}$ mice showed a reduction of the basal SOCS3 gene expression relative to that in the vehicle-treated IRS$2^{-/-}$mice. In addition, the responsiveness of leptin-induced SOCS3 gene expression was enhanced in the CL316243-treated IRS-2 $2^{-/-}$mice (Fig. 9c).

\section{Discussion}

We demonstrated in this study that lowering the body weight set point is crucial to overcoming genetically aberrant hypothalamic leptin signaling and thus obtaining a successful effect of dieting without incurring a rebound increase in body weight. Our results on the effects of CR and $\beta 3$-AR agonist treatments deserve to be emphasized: $\mathrm{CR}$ and $\beta 3$-AR agonist treatments exert differential impacts on dieting, although both induce recovery of STAT3 phosphorylation (Figs. 3a, b, 8a, b). We demonstrated that, under the condition of ad libitum feeding, $\beta 3$-AR agonisttreated mice showed a sustained reduction in body weight whereas CR mice failed to show a sustained reduction in body weight and became obese again after the release of CR (Fig. 5a). These experimental findings indicate that (1) CR cannot be an efficacious measure for lowering of the body weight set point and achieving ultimate resolution of obesity, (2) strategies other than CR are required to prevent a rebound increase in body weight after CR release, and (3) $\beta 3$-AR agonist treatment represents one effective way to resolve obesity by overcoming the genetically aberrant hypothalamic signaling, as seen in $I R S-2^{-/-}$mice.

The involvement of leptin resistance in determining the body weight set point has not yet been clarified. Leptin resistance, defined as diminished intracellular responses in the hypothalamus or inadequate weight reduction in 
Fig. $7 \beta 3-A R$ agonist treatment ameliorated leptin resistance in $I R S-2^{-1-}$ mice. Changes in a food intake and $\mathbf{b}$ body weight in the vehicle-treated IRS-2 ${ }^{-I-}$ mice (IRS-2 $2^{-1-}$ vehicle), $\beta 3-\mathrm{AR}$ agonist-treated $I R S-2^{-/-}$mice $\left(\right.$ IRS $\left.-2^{-1-} C L-316243\right)$, and wild-type mice $(W T)$ during the 12-h period after leptin or saline injection ( $n=5-9$ per group). Data are presented as the mean \pm SEM. $* * p<0.01$, $* p<0.05$

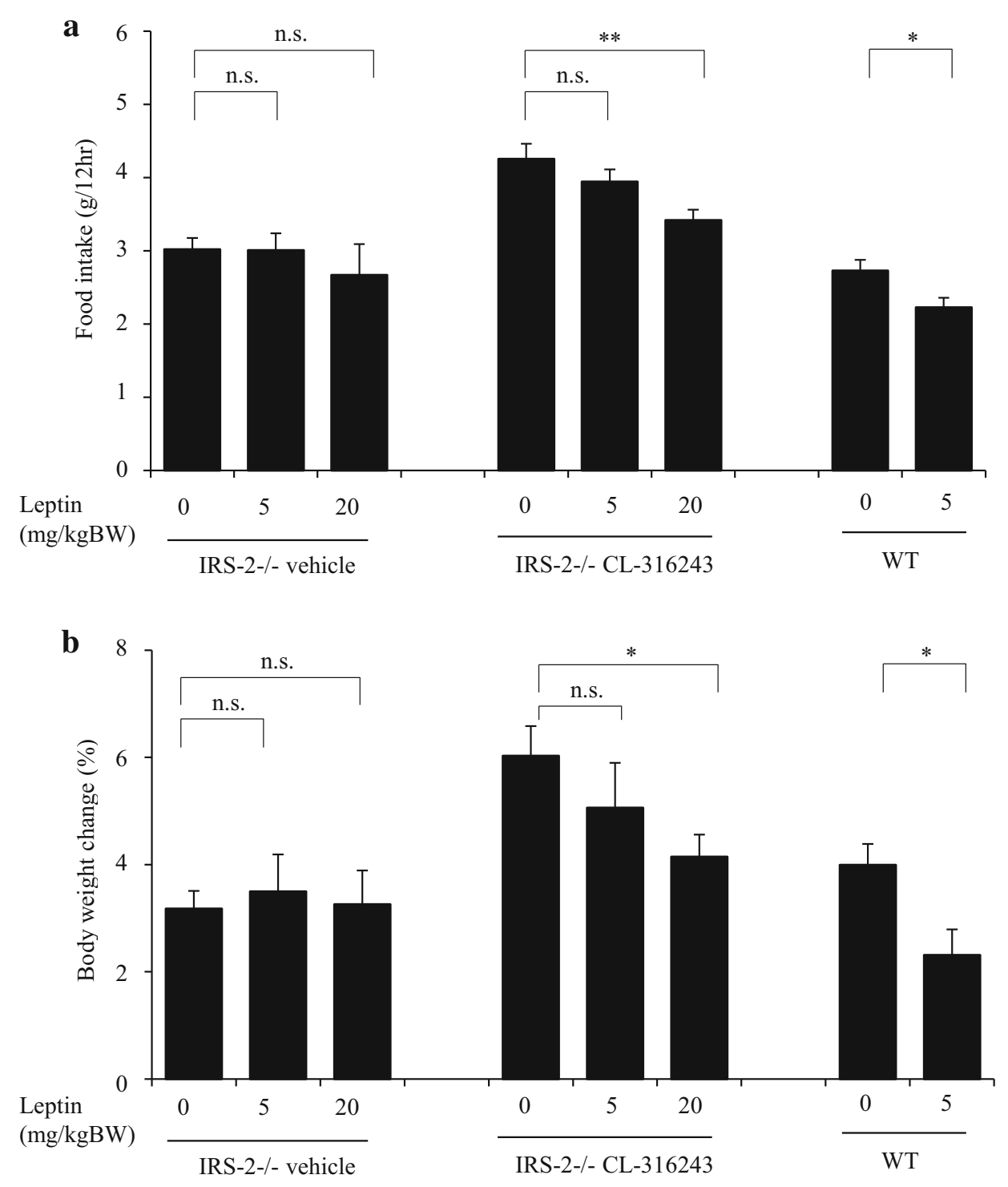

response to leptin administration, exists in the majority of obese individuals, including rodents and humans [15-17]. Leptin resistance is also considered both a consequence and a cause of obesity [37]. Our data on $I R S-2^{-1-}$ mice under CR showed two independent reasons for the development of leptin resistance: first, a primary defect in hypothalamic IRS-2/PI3K signaling; second, acquired leptin resistance [12] or cellular leptin resistance [13], as represented by reduced STAT3 phosphorylation. The primary genetic defect in IRS-2/PI3K signaling promotes a vicious cycle of obesity, hyperleptinemia, and acquired leptin resistance, causing the body weight set point to be reached. Since the body weight of the mice rebounded rapidly after $\mathrm{CR}$ release, it was concluded that the resolution of acquired leptin resistance by $\mathrm{CR}$ did not affect the body weight set point.
How can $\beta 3-\mathrm{AR}$ agonist treatment successfully lower the body weight set point? As $\beta 3$-AR agonist treatment increases energy expenditure [38-40] and lowers the serum leptin levels [41], $\beta 3$-AR agonists can serve as anti-obesity drugs. During the first 2 weeks of $\beta 3-A R$ agonist treatment, the adiposity of the $I R S-2^{-/-}$mice in this study remained unaltered despite the increased energy expenditure; a certain "body weight-maintaining" mechanism may have been operating to promote food intake (Fig. 6e). This increased food intake may be explained, at least in part, by reduced circulating leptin levels (Fig. 6f). As previously reported, the $\beta 3$-AR agonist reduced leptin gene expression in adipocytes and adipose tissue [32, 41-43]. This seems to be a direct effect of $\beta 3$-AR agonists. Since the improvement in leptin sensitivity may have been canceled out by the lower serum leptin concentration, the total amount of 
Fig. $8 \beta 3-A R$ agonist treatment restored leptin-induced STAT3 phosphorylation but exerted no effect on the PI3K activity in the hypothalamus of $I R S-2^{-1-}$ mice. a Immunoblotting of phospho- or non-phosphoSTAT3 in the hypothalamus of vehicle-treated IRS - $2^{-I-}$ mice $\left(I R S-2^{-1-}\right.$ vehicle $)$ and $\beta 3-\mathrm{AR}$ agonist-treated $I R S-2^{-I-}$ mice (IRS-2 $\left.{ }^{-/-} C L-316243\right)$ after leptin injection. b Intensities of the bands corresponding to phospho-specific STAT3 corrected for non-phosphoSTAT3 expression. c The bar graph shows the PI3K activity in each group. White bars saline injection, black bars leptin injection. Data are presented as the mean \pm SEM of three independent experiments. $* * p<0.01, * p<0.05$ $\mathbf{a}$

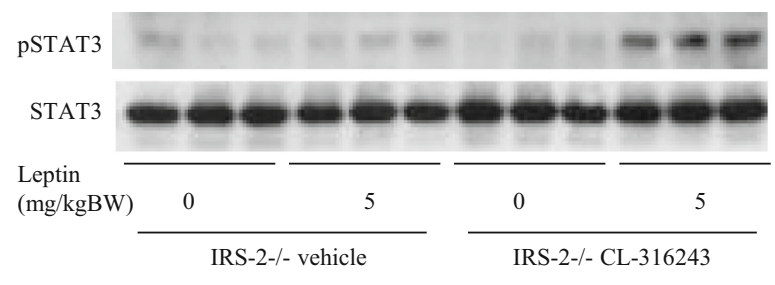

c

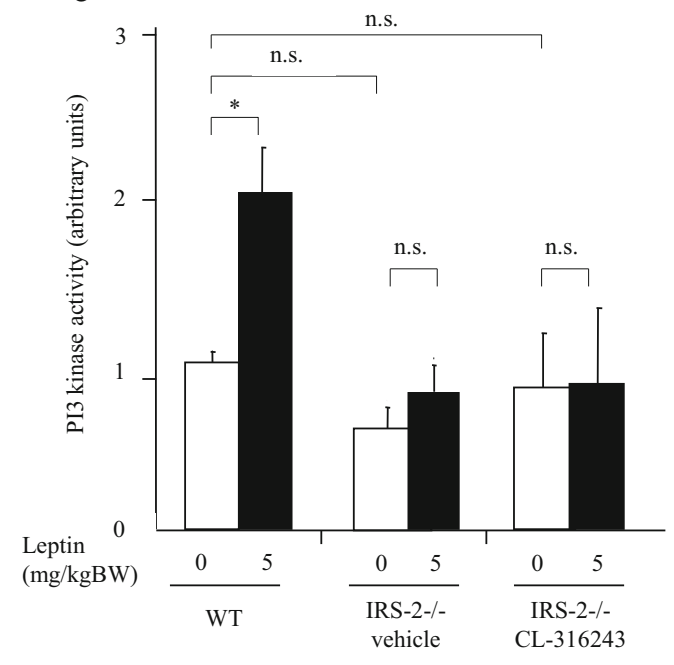

b

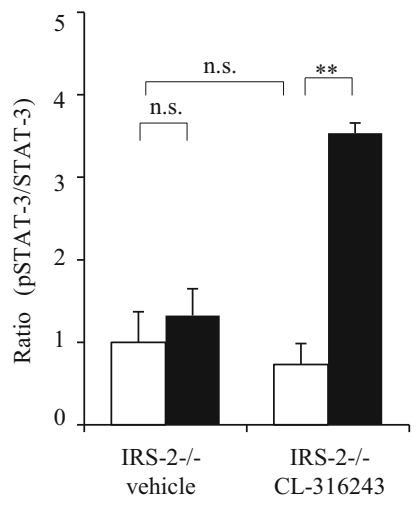

leptin activity may have been lower despite the recovery of leptin sensitivity. That may have been why we observed increased food intake by the $\beta 3$-AR agonist-treated IRS$2^{-/-}$mice despite the recovery from leptin resistance. The increase in food intake is also explained by the central responses to prevent fat store depletion triggered by the increased energy expenditure, as proposed by the lipostat hypothesis [2]. After 2 weeks of $\beta 3$-AR agonist treatment, the mice began to lose body weight, with partial restoration of the suppressive effect of leptin on food intake and body weight gain (Fig. 7). Although STAT3 phosphorylation was fully restored in the $\beta 3$-AR agonist-treated mice, this is not sufficient to sustain the body weight reduction, as evidenced by the body weight changes in CR mice. Thus, it is highly possible that $\beta 3$-AR agonist treatment improved leptin resistance, not only at the hypothalamic STAT3 phosphorylation level, but also at the level of other pathways either lying downstream or independent of leptin signaling in the hypothalamus, which may determine the body weight set point. The $\beta 3$-AR agonist-induced increase in energy expenditure may work on those pathways, thus lowering the body weight set point to achieve sustainable body weight loss. Lowering the body weight set point is the key to maintaining reduced body weight [1-4]. Since we demonstrated that an improvement in leptin sensitivity itself does not affect the body weight set point (Figs. 2a, 5), but an increase in energy expenditure can lower the body weight set point (Figs. 6a, 7), we concluded that an increase in energy expenditure is the key to lowering the body weight set point and maintaining a reduced body weight.

It is of interest that $\beta 3-\mathrm{AR}$ agonist treatment and physical exercise share common pathways in the central nervous system (CNS), as demonstrated in a previous study [44]. What are the clinical implications of this finding? It is possible that certain genetic backgrounds force obese subjects to develop obesity as in the case of genetically disordered IRS $-2^{-I-}$ mice, in which CR per se is not able to lower the original body weight set point. Thus, treatments to alter the body weight set point itself, including $\beta 3$-AR agonist administration and exercise, should be administered for patients who have a genetic background strongly predisposing them to obesity.

How does $\beta 3$-AR agonist treatment increase energy expenditure? The effect of $\beta 3$-AR agonists is not limited to BAT. The existence of beige cells, which reside in subcutaneous white adipose tissue and begin to express BATspecific genes and exhibit a BAT-like phenotype after cold 
Fig. 9 Chronic $\beta 3$-AR agonist (CL-316243) treatment increased POMC gene expression, decreased NPY gene expression, and restored SOCS3 gene expression in the hypothalamus of $I R S-2^{-/-}$mice after intraperitoneal leptin administration. Gene expression of a POMC, b NPY, and c SOCS3 in the hypothalamus of the vehicle-treated IRS-2 ${ }^{-/-}$ mice (IRS-2-l- vehicle), $\beta 3$-AR agonist-treated $I R S-2^{-l-}$ mice (IRS-2 $\left.{ }^{-1-} C L-316243\right)$, and wild-type mice (WT) were measured using quantitative RT-PCR and normalized against the gene expression of $18 \mathrm{~S}$ ( $n=12-18$ per group). Data are presented as the mean \pm SEM. White bars saline injection, black bars leptin injection. $* * p<0.01, * p<0.05$
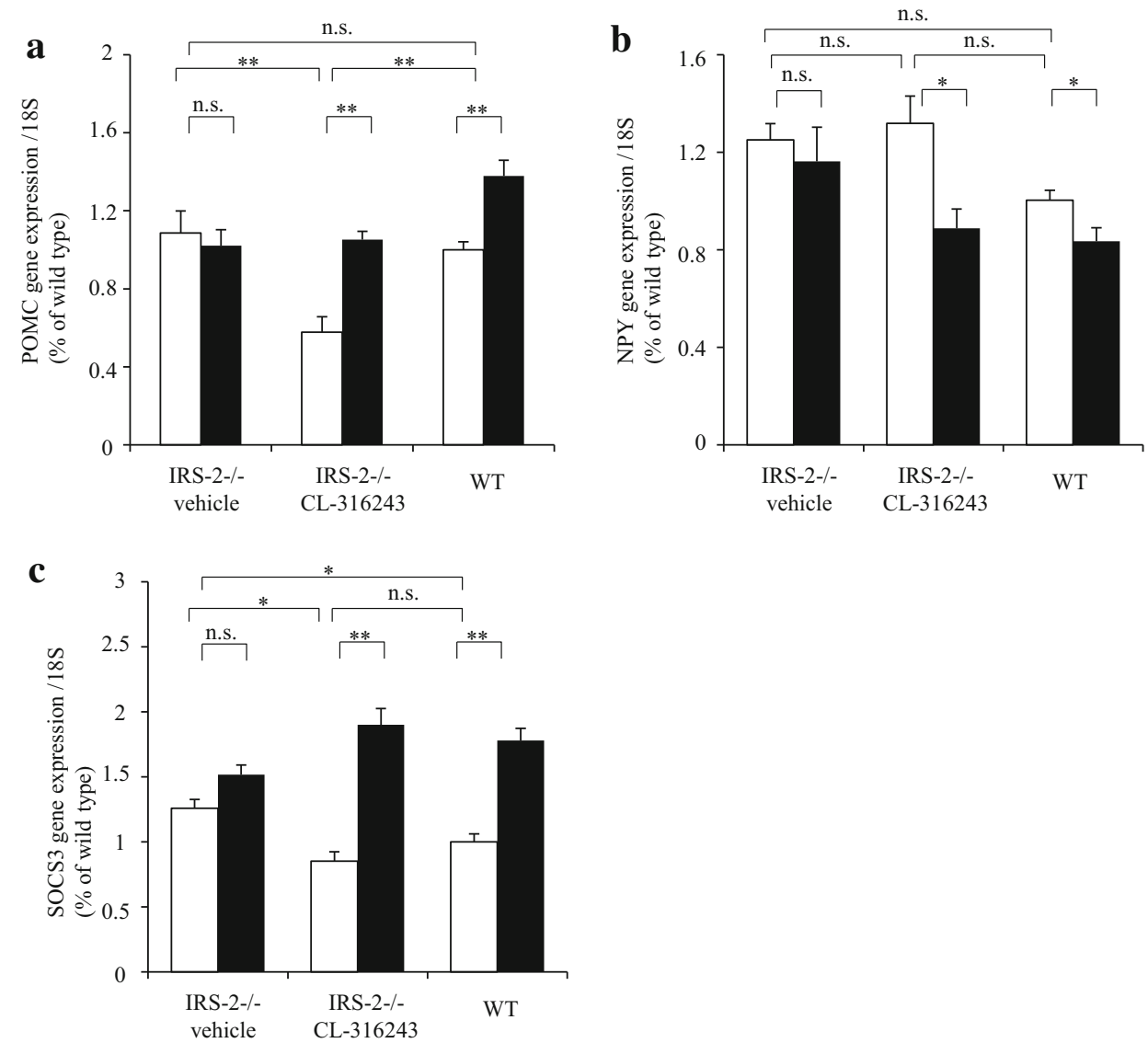

stimulation, was recently reported [45-48]. In fact, the administration of a $\beta 3$-AR agonist has been reported to induce beige cells in inguinal white adipose tissue [49-52]. These browning phenomena are also involved in the $\beta 3-\mathrm{AR}$ agonist-mediated increase in energy expenditure.

HFD administration is known to elevate the body weight set point, independent of STAT3 phosphorylation [18]. It would seem that HFD helps to elevate the body weight set point by impairing leptin signaling, including by increasing endoplasmic reticulum (ER) stress and inducing inflammation in the hypothalamus [53]. In fact, the body weight set point of HFD-fed $o b / o b$ mice, in which the serum leptin levels were clamped to the levels seen in normal chow-fed wild-type mice, as a consequence of which the STAT3 phosphorylation level was also comparable to that in normal chow-fed wild-type mice, was similar to that in HFDfed wild-type mice [18]. These data suggest that HFD itself, and not the STAT3 phosphorylation level, was responsible for the elevated body weight set point. In addition, the body weight of HFD-fed leptin-overexpressing transgenic mice $[54,55]$ eventually caught up with the body weight of HFD-fed wild-type mice. Thus, HFD directly transmits signals to upregulate the body weight set point, independent of the serum leptin and hypothalamic
STAT3 phosphorylation levels. Attenuation of the feedback signal to defend the original adiposity associated with HFD may be the basis of the "settling point theory" [4, $56]$.

What are the clinical implications of the amelioration of acquired leptin resistance by CR? From the therapeutic viewpoint, leptin administration should be recommended after weight reduction is achieved, because leptin is more effective in a calorie-restricted leaner state (Fig. 2). In fact, Rosenbaum and Leibel have demonstrated in a series of human studies that an enforced weight-reduced state is regarded as a condition of relative leptin insufficiency, and that low-dose leptin supplementation effectively maintains the reduced body weight in weight-reduced humans by reversing the skeletal muscle, autonomic, and neuroendocrine adaptations [57, 58]. Leptin supplementation, however, was not so effective at reducing the body weight set point in obese subjects, as previously reported [59].

Acquired leptin resistance is largely explained by reduced STAT3 phosphorylation induced by hyperleptinemia [18]. Although the CR-induced improvement of acquired leptin resistance did not affect the body weight set point, genetic defects of the genes involved in this feedback 
system affected the body weight set point, as seen in mice deficient in SOCS3 $[60,61]$ and SOCS3/protein-tyrosine phosphatase-1B (PTP1B) double mutants [62].

We evaluated the degree of leptin resistance by measuring alterations in the food intake and body weight, as well as by evaluating the STAT3 phosphorylation level and neuropeptide expression status in the hypothalamus after leptin administration. The leptin resistance measured by this assay may be useful for evaluating the potential efficacy of exogenously administered leptin. However, to elucidate the molecular mechanisms of obesity, this assay should be performed after body weight correction comparable to that of the wild-type mice at the very least, because genetic and acquired factors contribute to the development of leptin resistance [13]. At the same time, the manner of administration of leptin may need to be debated [14], because bolus administration and continuous infusion of leptin may elicit distinct consequences. In our experiments, leptin was injected as a single bolus daily, so the effect of chronic administration of physiological concentrations of leptin remains to be evaluated.

In conclusion, the recovery of leptin sensitivity by $\mathrm{CR}$ is not sufficient to alter the body weight set point, as illustrated by the rebound increase in body weight after release from the CR in the IRS-2 $2^{-1-}$ mice. This is considered to be because CR can improve only "acquired" leptin resistance, as reflected by the restored STAT3 phosphorylation, with normalization of the hyperleptinemia. Resolution of acquired leptin resistance per se cannot change the body weight set point. In contrast, the $\beta 3$-AR agonist effectively lowered the body weight set point, with the reduced body weight successfully maintained for as long as the drug was administered. Interestingly, reduction of the body weight set point was achieved even when the recovery of the suppressive effects of leptin on food intake and body weight gain was not complete in the $\beta 3$-AR agonist-treated mice (Fig. 7). These data indicate that the determination of body weight set point is dissociated from the physiological effects of exogenous leptin on food intake and body weight gain as well as STAT3 phosphorylation and neuropeptide gene expression.

Treatments that increase energy expenditure, including $\beta 3$-AR agonist administration and physical exercise, may improve the leptin sensitivity in such a way that the body weight set point is sufficiently lowered (as mediated by pathways independent of STAT3), in part because of the agonist's effect on fat oxidation. Further investigations will be required for a more detailed clarification of the mechanisms involved.

Acknowledgments We thank Dr. Hironobu Yoshimatsu (Oita University), Dr. Yoichi Ueta (University of Occupational and Environmental Health), Dr. Ryozo Nagai, Dr. Junji Kamon, Dr. Yusuke
Ito, Dr. Hidemi Sato, Dr. Wataru Yano, Dr. Atsushi Tsuchida (Tokyo University), and Dr. Shiho Fujisaka (Toyama University) for their helpful discussions. We also wish to thank Tadahiko Tsuchiya, Hirofumi Nishizono (Toyama University), C.Kokaki-Kaizuka, A. Nagano, H. Chiyonobu (Tokyo University), Tomomi Kubo, Kana Sugihara, Aminuddin, Akiko Takikawa, Takako Kabutoyama, and Junko Ishiguro (Toyama Universtity) for their excellent technical assistance and mouse husbandry.

Conflict of interest Naoto Kubota received a research grant from Sanofi K.K. The other authors declare that they have no conflict of interest.

Ethical standard All institutional and national guidelines for the care and use of laboratory animals were followed.

\section{References}

1. Leibel RL. Molecular physiology of weight regulation in mice and humans. Int J Obes. 2008;32(Suppl 7):S98-108.

2. Kennedy GC. The role of depot fat in the hypothalamic control of food intake in the rat. Proc R Soc Lond B Biol Sci. 1953;140:578-96.

3. Anderson JW, Konz EC, Frederich RC, Wood CL. Long-term weight-loss maintenance: a meta-analysis of US studies. Am J Clin Nutr. 2001;74:579-84.

4. Speakman JR, Levitsky DA, Allison DB, et al. Set points, settling points and some alternative models: theoretical options to understand how genes and environments combine to regulate body adiposity. Dis Models Mech. 2011;4:733-45.

5. Friedman JM. Leptin at 14 y of age: an ongoing story. Am J Clin Nutr. 2009;89:973S-9S.

6. Morton GJ, Cummings DE, Baskin DG, Barsh GS, Schwartz MW. Central nervous system control of food intake and body weight. Nature. 2006;443:289-95.

7. Spiegelman BM, Heinrich R. Biological control through regulated transcriptional coactivators. Cell. 2004;119:157-67.

8. Zhang Y, Proenca R, Maffei M, et al. Positional cloning of the mouse obese gene and its human homologue. Nature. 1994;372:425-32.

9. Tam J, Fukumura D, Jain RK. A mathematical model of murine metabolic regulation by leptin: energy balance and defense of a stable body weight. Cell Metab. 2009;9:52-63.

10. Farooqi IS, Jebb SA, Langmack G, et al. Effects of recombinant leptin therapy in a child with congenital leptin deficiency. N Engl J Med. 1999;341:879-84.

11. Farooqi IS, O'Rahilly S. Mutations in ligands and receptors of the leptin-melanocortin pathway that lead to obesity. Nat Clin Pract Endocrinol Metab. 2008;4:569-77.

12. Montez JM, Soukas A, Asilmaz E, et al. Acute leptin deficiency, leptin resistance, and the physiologic response to leptin withdrawal. Proc Natl Acad Sci USA. 2005;102:2537-42.

13. Myers MG Jr, Leibel RL, Seeley RJ, Schwartz MW. Obesity and leptin resistance: distinguishing cause from effect. Trends Endocrinol Metab. 2010;21:643-51.

14. Myers MG Jr, Heymsfield SB, Haft C, et al. Challenges and opportunities of defining clinical leptin resistance. Cell Metab. 2012;15:150-6.

15. El-Haschimi K, Pierroz DD, Hileman SM, Bjorbaek C, Flier JS. Two defects contribute to hypothalamic leptin resistance in mice with diet-induced obesity. J Clin Invest. 2000;105:1827-32.

16. Frederich RC, Hamann A, Anderson S, et al. Leptin levels reflect body lipid content in mice: evidence for diet-induced resistance to leptin action. Nat Med. 1995;1:1311-4. 
17. Van Heek M, Compton DS, France CF, et al. Diet-induced obese mice develop peripheral, but not central, resistance to leptin. J Clin Invest. 1997;99:385-90.

18. Knight ZA, Hannan KS, Greenberg ML, Friedman JM. Hyperleptinemia is required for the development of leptin resistance. PLoS One. 2010;5:e11376.

19. Bruning JC, Gautam D, Burks DJ, et al. Role of brain insulin receptor in control of body weight and reproduction. Science. 2000;289:2122-5.

20. Burks DJ, Font de Mora J, Schubert M, et al. IRS-2 pathways integrate female reproduction and energy homeostasis. Nature. 2000;407:377-82.

21. Niswender KD, Morton GJ, Stearns WH, et al. Intracellular signalling. Key enzyme in leptin-induced anorexia. Nature. 2001;413:794-5.

22. Obici S, Feng Z, Karkanias G, Baskin DG, Rossetti L. Decreasing hypothalamic insulin receptors causes hyperphagia and insulin resistance in rats. Nat Neurosci. 2002;5:566-72.

23. Metlakunta AS, Sahu M, Sahu A. Hypothalamic phosphatidylinositol 3-kinase pathway of leptin signaling is impaired during the development of diet-induced obesity in FVB/N mice. Endocrinology. 2008;149:1121-8.

24. Tobe K, Suzuki R, Aoyama M, et al. Increased expression of the sterol regulatory element-binding protein-1 gene in insulin receptor substrate-2(-/-) mouse liver. J Biol Chem. 2001;276:38337-40.

25. Kubota N, Terauchi Y, Tobe K, et al. Insulin receptor substrate 2 plays a crucial role in beta cells and the hypothalamus. J Clin Invest. 2004;114:917-27.

26. Lin X, Taguchi A, Park S, et al. Dysregulation of insulin receptor substrate 2 in beta cells and brain causes obesity and diabetes. J Clin Invest. 2004;114:908-16.

27. Suzuki R, Tobe K, Aoyama M, et al. Both insulin signaling defects in the liver and obesity contribute to insulin resistance and cause diabetes in Irs2(-/-) mice. J Biol Chem. 2004;279:25039-49.

28. Suzuki R, Tobe K, Aoyama M, et al. Expression of DGAT2 in white adipose tissue is regulated by central leptin action. J Biol Chem. 2005;280:3331-7.

29. Liu X, Perusse F, Bukowiecki LJ. Mechanisms of the antidiabetic effects of the beta 3-adrenergic agonist CL-316243 in obese Zucker-ZDF rats. Am J Physiol. 1998;274:R1212-9.

30. Arch JR. Beta(3)-adrenoceptor agonists: potential, pitfalls and progress. Eur J Pharmacol. 2002;440:99-107.

31. Weyer C, Tataranni PA, Snitker S, Danforth E Jr, Ravussin E. Increase in insulin action and fat oxidation after treatment with CL 316,243, a highly selective beta3-adrenoceptor agonist in humans. Diabetes. 1998;47:1555-61.

32. Kato H, Ohue M, Kato K, et al. Mechanism of amelioration of insulin resistance by beta3-adrenoceptor agonist AJ-9677 in the KK-Ay/Ta diabetic obese mouse model. Diabetes. 2001;50:113-22.

33. Tobe $\mathrm{K}$, Tamemoto $\mathrm{H}$, Yamauchi $\mathrm{T}$, et al. Identification of a $190-\mathrm{kDa}$ protein as a novel substrate for the insulin receptor kinase functionally similar to insulin receptor substrate-1. J Biol Chem. 1995;270:5698-701.

34. Fujisaka S, Usui I, Kanatani Y, et al. Telmisartan improves insulin resistance and modulates adipose tissue macrophage polarization in high-fat-fed mice. Endocrinology. 2011;152:1789-99.

35. Wilsey J, Scarpace PJ. Caloric restriction reverses the deficits in leptin receptor protein and leptin signaling capacity associated with diet-induced obesity: role of leptin in the regulation of hypothalamic long-form leptin receptor expression. J Endocrinol. 2004;181:297-306.

36. Gettys TW, Harkness PJ, Watson PM. The beta 3-adrenergic receptor inhibits insulin-stimulated leptin secretion from isolated rat adipocytes. Endocrinology. 1996;137:4054-7.
37. Scarpace PJ, Matheny M, Tumer N, Cheng KY, Zhang Y. Leptin resistance exacerbates diet-induced obesity and is associated with diminished maximal leptin signalling capacity in rats. Diabetologia. 2005;48:1075-83.

38. Bloom JD, Dutia MD, Johnson BD, et al. Disodium $(R, R)-5-[2-$ [[2-(3-chlorophenyl)-2-hydroxyethyl]-amino] propyl]-1,3-benzodioxole-2,2-dicarboxylate (CL 316,243). A potent beta-adrenergic agonist virtually specific for beta 3 receptors. A promising antidiabetic and antiobesity agent. J Med Chem. 1992;35:3081-4.

39. Himms-Hagen J, Cui J, Danforth E Jr, et al. Effect of CL316,243 , a thermogenic beta 3 -agonist, on energy balance and brown and white adipose tissues in rats. Am $\mathrm{J}$ Physiol. 1994;266:R1371-82.

40. Inokuma $\mathrm{K}$, Okamatsu-Ogura $\mathrm{Y}$, Omachi A, et al. Indispensable role of mitochondrial UCP1 for antiobesity effect of beta3-adrenergic stimulation. Am J Physiol Endocrinol Metab. 2006;290:E1014-21.

41. Ghorbani M, Himms-Hagen J. Treatment with CL 316,243, a beta 3 -adrenoceptor agonist, reduces serum leptin in rats with diet- or aging-associated obesity, but not in Zucker rats with genetic (fa/fa) obesity. Int J Obes Relat Metab Disord J Int Assoc Study Obes. 1998;22:63-5.

42. Cammisotto PG, Bukowiecki LJ. Mechanisms of leptin secretion from white adipocytes. Am J Physiol Cell Physiol. 2002;283:C244-50.

43. Zhang Y, Matheny M, Zolotukhin S, Tumer N, Scarpace PJ. Regulation of adiponectin and leptin gene expression in white and brown adipose tissues: influence of beta3-adrenergic agonists, retinoic acid, leptin and fasting. Biochim Biophys Acta. 2002;1584:115-22.

44. Krawczewski Carhuatanta KA, Demuro G, Tschop MH, et al. Voluntary exercise improves high-fat diet-induced leptin resistance independent of adiposity. Endocrinology. 2011;152:2655-64.

45. Harms M, Seale P. Brown and beige fat: development, function and therapeutic potential. Nat Med. 2013;19:1252-63.

46. Cousin B, Cinti S, Morroni M, et al. Occurrence of brown adipocytes in rat white adipose tissue: molecular and morphological characterization. J Cell Sci. 1992;103(Pt 4):931-42.

47. Guerra C, Koza RA, Yamashita H, Walsh K, Kozak LP. Emergence of brown adipocytes in white fat in mice is under genetic control. Effects on body weight and adiposity. J Clin Invest. 1998;102:412-20.

48. Vitali A, Murano I, Zingaretti MC, et al. The adipose organ of obesity-prone C57BL/6J mice is composed of mixed white and brown adipocytes. J Lipid Res. 2012;53:619-29.

49. Contreras GA, Lee YH, Mottillo EP, Granneman JG. Inducible brown adipocytes in subcutaneous inguinal white fat: the role of continuous sympathetic stimulation. Am J Physiol Endocrinol Metab. 2014;307:E793-9.

50. Ghorbani M, Claus TH, Himms-Hagen J. Hypertrophy of brown adipocytes in brown and white adipose tissues and reversal of diet-induced obesity in rats treated with a beta3-adrenoceptor agonist. Biochem Pharmacol. 1997;54:121-31.

51. Granneman JG, Li P, Zhu Z, Lu Y. Metabolic and cellular plasticity in white adipose tissue I: effects of beta3-adrenergic receptor activation. Am $\mathrm{J}$ Physiol Endocrinol Metab. 2005;289:E608-16.

52. Himms-Hagen J, Melnyk A, Zingaretti MC, et al. Multilocular fat cells in WAT of CL-316243-treated rats derive directly from white adipocytes. Am J Physiol Cell Physiol. 2000;279:C670-81.

53. Cai D, Liu T. Hypothalamic inflammation: a double-edged sword to nutritional diseases. Ann N Y Acad Sci. 2011;1243:E1-39.

54. Ogus S, Ke Y, Qiu J, Wang B, Chehab FF. Hyperleptinemia precipitates diet-induced obesity in transgenic mice overexpressing leptin. Endocrinology. 2003;144:2865-9. 
55. Tanaka T, Hidaka S, Masuzaki H, et al. Skeletal muscle AMPactivated protein kinase phosphorylation parallels metabolic phenotype in leptin transgenic mice under dietary modification. Diabetes. 2005;54:2365-74.

56. Wirtshafter D, Davis JD. Set points, settling points, and the control of body weight. Physiol Behav. 1977;19:75-8.

57. Rosenbaum M, Goldsmith R, Bloomfield D, et al. Low-dose leptin reverses skeletal muscle, autonomic, and neuroendocrine adaptations to maintenance of reduced weight. J Clin Invest. 2005;115:3579-86.

58. Rosenbaum M, Murphy EM, Heymsfield SB, Matthews DE, Leibel RL. Low dose leptin administration reverses effects of sustained weight-reduction on energy expenditure and circulating concentrations of thyroid hormones. J Clin Endocrinol Metab. 2002;87:2391-4.
59. Heymsfield SB, Greenberg AS, Fujioka K, et al. Recombinant leptin for weight loss in obese and lean adults: a randomized, controlled, dose-escalation trial. JAMA. 1999;282:1568-75.

60. Howard JK, Cave BJ, Oksanen LJ, et al. Enhanced leptin sensitivity and attenuation of diet-induced obesity in mice with haploinsufficiency of Socs3. Nat Med. 2004;10:734-8.

61. Mori H, Hanada R, Hanada T, et al. Socs 3 deficiency in the brain elevates leptin sensitivity and confers resistance to diet-induced obesity. Nat Med. 2004;10:739-43.

62. Briancon N, McNay DE, Maratos-Flier E, Flier JS. Combined neural inactivation of suppressor of cytokine signaling-3 and protein-tyrosine phosphatase-1B reveals additive, synergistic, and factor-specific roles in the regulation of body energy balance. Diabetes. 2010;59:3074-84. 